TRADUÇÃOO 


\title{
ÉTIENNE SOURIAU: UMA ONTOLOGIA SINGULAR
}

\author{
ÉTIENNE SOURIAU: UNE ONTOLOGIE SINGULIĖRE
}

Dominique Chateau

tradução de Angela Grando e Darcília Moysés

Dominique Chateau est philosophe français. Il a rédigé de nombreux ouvrages et articles en esthétique, philosophie de l'art et en études cinématographiques. Professeur, il en-seigne à l'Université Paris-l Panthéon-Sorbonne depuis 1974 la philosophie de l'art, l'es-thétique et les études cinématographiques.. 
Étienne Souriau: Uma Ontologia Frequentemente, eu me censuro, silenciosamente, por não ter militado o suficiente pelo (re) conhecimento de Étienne Souriau. Na verdade, eu o fiz: a cada ano, falei com meus alunos sobre suas teorias estéticas ou filosóficas, bem como sobre sua contribuição para a teoria do cinema; em vários livros ou artigos, discuti ou analisei suas propostas; entre outros, em Filosofia de uma Arte Moderna: o cinema [1] $]^{1}$, dedico um capítulo inteiro às consequências de sua divisão entre o representativo e o "apresentativo" quanto à Sétima arte. A lista de minhas alusões ou referências a seu trabalho não se encerram aí. Mas essa crítica que eu evoco agora não thes diz respeito. Trata-se, ao contrário, de dedicar a Souriau um estudo inteiro, tão exaustivo quanto possível, em todo caso, visando a apresentá-lo e expressando toda a admiração que tenho por ele, e que eu acredito objetiva.

Não há necessidade de ampliar sua obra com ditirambos forçados. Pela quantidade, primeiramente, ela impressiona, na variedade, também. Eu, de minha parte, acrescento que ela é qualitativamente considerável. Ela contém uma parte da história intelectual de sua época, essa história que foi escrita no final da guerra e que nós (os da minha geração, pelo menos) herdamos - razão a mais para se culpar por não o testemunhar suficientemente. Com as novas pistas que abre, ela traz, certamente, muitos traços de um pensamento de época um pouco esquecido. Nomes com estranhas consonâncias pontilham; citações latinas como já não se fazem mais; maneiras de dizer extintas. Eu estarei interessado, aliás, neste aspecto à primeira vista, estranho. Quem são esses Prémontval e Strada, com nomes dignos de um romance de capa e espada, que Sou-

1 Dominique Chateau, Philosophie d'un art moderne : le cinéma, Paris, L' Harmattan, coll. "Champs visuels", 2009, chap. IX, "L'ontologie filmique". riau invoca? Qual é essa peculiaridade estranha de que ele gosta tão particularmente? O que significa o punctum saliens lucidum, que caracteriza sua interpretação pessoal do cogito?

Essas peculiaridades afloram todas quando surge um propósito ontológico. Se há um problema central na filosofia de Souriau é, exatamente, o da ontologia. Não a ontologia do ser abstrato, mas sim, a ontologia apreendida no desafio da existência, modos de ser, de representação, de arte. Por essa razão, esse grande filósofo faz parte dos pensamentos que me inspiram.

No que diz respeito à ontologia, Souriau se distingue pela vontade de reavivar os problemas tradicionais que outros abandonam. Isso foi cedo constatado, em 1938, com a sua iluminada definição da alma como sendo a suposição que se faz diante do outro de um "universo" constituído pelo conjunto estruturado e mutável "de seus pensamentos, suas ideias, seu comportamento, suas tendências", um "microcosmo, que é possível conceber (ao certo ou errado, o que for) sobre o modelo de um ser e um mundo" $[2]^{2}$. Reteremos a palavra "universo" para definir a alma (poderíamos falar sobre o mundo, um mundo possível encarnado por um individuo) e o link analógico que poderia ligá-lo ao "universo fílmico". Retomo, mais adiante, as ideias transversais que animam uma obra que parece, à primeira vista, disseminada e esvoaçante.

No mesmo texto, no lugar da palavra conceber, Souriau usa a palavra "representação". Sabe-se que ele era um filósofo particularmente atento à representação; suas pesquisas sobre as correspondências das artes e sobre o cinema confirmam isso. Neste caso, ele quer dizer que vemos o outro como uma alma, talvez erradamente, mas o que importa é que o fazemos.

2 Étienne Souriau, Avoir une âme. Essai sur les existences virtuelles, Paris, Les Belles Lettres, Annales de l'université de Lyon.Troisième série, Lettres, fascicule V, 1938,p. 13. 
Aqui ele se interessa menos pelos "processos representativos" que permitem a representação da alma, que pelo próprio fato da suposição, especialmente por se tratar, em um nível prático, de justificar algo que um passivo metafísico pesado condenara à "desgraça": supor a alma no outro, fixar em uma representação o mundo virtual e instável do outro, é ceder a um modo de "conhecimento que pode elevar-se àquele do singular".

Ontologia singular, diz meu título. Acrescento: ontologia da singularidade, em busca desta propriedade de ser que não se despreza. Algumas pessoas, é claro, rejeitam-na como inacessível ao pensamento, reservada ao ser no mundo - ou seja, para viver em vez de comentar. Souriau, pelo contrário, aceita esse desafio. Sem dúvida, a arte e sua obsessão por representações singulares têm um papel mais que subjacente em sua convicção. Ao mesmo tempo, longe de negar o fato de que a singularidade é baseada na experiência individual, no vivido e no sentido, faz dela teoria.

Um ano depois da alma, uma palavrinha curiosa aparece no trabalho de Souriau e atrai a atenção: a de patuidade. Ela acompanha o conceito seminal de instauração:

Que nos permitam indicar sucintamente a qual vocabulário técnico nós nos adequamos nestes estudos: denominamos instauração qualquer processo, abstrato ou concreto, de operações criadoras, construtoras, ordenadoras ou evolutivas, que leva à posição de um ser na sua patuidade, isto é, com um brilho suficiente da realidade; e estabelecer tudo o que é apropriado para tal processo [3] $]^{3}$.

Concentremo-nos na expressão curiosa: “[...] que leva à posição de um ser em sua "patuidade". Várias definições de "patuidade" na Internet registram: sentir empatia, mas é uma falsa eti-

3 Étienne Souriau, L'Instauration philosophique, Paris, librairie Félix Alcan, "Bibliothèque de philosophie contemporaine”, 1939, p. 10, note 1 . Souligné par moi. mologia. Patuidade, que é sem h, não pertence à série de derivados de pathos. Ela vem de patere, o que significa: estar aberto, viável, acessível, disponibilizado, estar descoberto, dar ocasião para, estar diante dos olhos, visíveis; ser claro, óbvio, patent (donde patet: é claro que; e patens: descoberto, aberto, evidente, manifesto, patente), ou mesmo expandir-se (um país, uma ciência). Souriau não inventou a palavra que procede do perfeito de patere: patui, patuit. De onde vem ela?

O filósofo esclarece esse ponto no início de $A$ Instauração [4]

Você supõe, criança, que você existe; que o mundo existe, e você deduz daí o seu conhecimento daquilo que é, como uma simples combinação, como uma simples adaptação mútua dessas duas coisas. Ora, eu não digo absolutamente que você não existe, mas que você só existe imperfeitamente, de um modo confuso, a meio caminho entre a existência real e a falta de realidade, o que pode até levar à ausência de existência. Pois a própria existência precisa da realidade, para ser verdadeira existência, e existência de algo ou de alguém. Ou, pelo menos, existem muitos tipos de existências. Mas nossa existência real, concreta e individual é quase sempre proposta como a ser realizada.Você realizaria sua realidade se pudesse, obviamente e por si mesmo, em sua "aseidade" como Premontval disse; na" patuidade" de seu ser como dizia Strada, em seu esplendor total, em sua presença ao mesmo tempo singular e essencial - e isso levanta o problema da verdade. Assim, você mesmo que acredita existir, existe apenas na medida em que participa mais ou menos do que seria sua existência real; e é simplesmente em relação ao que ela seria, que você existe, você, atualmente.

Esse esclarecimento introduz, primeiramente, outro termo incomum, aseidade e duas fon-

4 lbid., p. 6. 
tes não menos estranhas. O primeiro autor citado, Premontval, mais precisamente André-Pierre Le Guay de Premontval, é evocado por Diderot em Jacques o fatalista, principalmente por ter-se apaixonado por seu aluno em aula de matemática $[5]^{5}$. Ele também publicou obras de filosofia, de metafísica, $[6]^{6}$ nas quais retomou o termo escolástico de aseidade (aseitas) [7]', o que é por si, a se, causa sui - talvez com uma referência a Spinoza. Souriau faz desse termo a hipótese de ser, manifestadamente, e para si mesmo, um estado hipotético que supõe a realização a que se opõe o estado real do ser que está em processo de vir a ser, em vias de se realizar.

O segundo autor invocado é ainda mais bizarro: Strada, cujo nome verdadeiro é Gabriel Jules Delarue, mas conhecido sob uma cascata de pseudônimos: Jules Strada, J. Strada, Strada J., J. Gabriel Strada, José de Strada. Na imprensa de Província, esse estranho personagem é taxado de "pintorpoeta Poitevino ", sua obra sendo composta por muitos quadros que foram quase todos destruídos quando de sua morte, com as milhares de páginas de sua obra final, intitulada Moi (Eu) e poemas "filosóficos", de estilo bastante pretensioso. Edouard Estaunie, em Souvenirs, diz de seu livro, o Ultimum Organum, que ele é "uma mina de

5 Voir La Bibliothèque électronique Du Québec, "À tous les vents”, vol. 824: version 1.0; <https://beq.ebooksgratuits. com/vents/Diderot-Jacques.pdf>, p. 120 (édition de référence: Montréal, Les Éditions du Bélier, “Ariès"). Son élève que Premontval épousa, Marie Anne Victoire Pigeon (fille de Jean Pigeon don't Premontval fut l'élève avant d'enseigner lui -même), était réputée excellente mathématicienne (voir M. Michaud (dir.),Biographie universelle ancienne et moderne, Paris, A. Thoisnier Desplaces, t. XXXIV, 1843-18..., p. 314). 6 André-Pierre Le Guay de Prémontval, Vues philosophiques ou Protestations et Déclarations sur les principaux objets des connaissances humaines, Berlin, Joachim Paul,1757, 2 vol. 7 Voir dans l'ouvrage précédent, le texte intitulé La Théologie de l'Être ou Chaîne d'Idées de l'Être jusqu'à Dieu, §IX, Du principe de l'aséité universelle, pp. 350 et 399.

8 Voir Philippe Landreau, "Gabriel-Jules Delarue (dit Strada)", Bulletin de la Société historique et scientifique, Quatrième série, $n^{\circ} 7,2012$. ideias novas, exibidas em um estilo pascaliano". Ele acrescenta ter percebido em Strada que ele, frequentemente, visitava o enorme manuscrito intitulado Moi, "a história da sua vida e do seu pensamento [...], uma soma de observações e conhecimentos dignos do maior interesse"10. Ele afirma, enfim, que descobriu tarde demais a morte de seu amigo: sua irmã, com quem Strada tinha uma disputa em nível religioso e que achava que a obra de seu irmão era "demoníaca", havia queimado seus livros, seus manuscritos e suas pinturas, exceto duas ou três pinturas salvas por sua fiel serva ${ }^{11}$.

Como em Premontval, encontra-se nele uma vasta ambição metafísica, a do Grande Sistema. Sua principal obra sobre esse assunto, publicada em 1865, é intitulada Ensaio de um ultimo ótimo ou Constituição científica do método ${ }^{12}$. Como poderia Souriau ter-se interessado por Strada? Presumivelmente, sua atenção foi atraída para ele pelo influente relatório preparado por Felix Ravaisson em 1889, A Filosofia na França no século XIX13, no qual não apenas Strada foi levado muito a sério, mais ainda onde também estava explicitada sua teoria do Ultimum Organum e sua "liberdade de pensamento" no campo ontológico, elogiada. Patuidade, é pois, um tema recorrente do livro de Strada.

Nele, ela concerne, primeiramente, a Deus:

0 método absoluto encontrado nos deve dar Deus sempre fixo, sempre presente; deve nos fazer senti-lo pelas leis imutáveis em todo desenvolvimento humano na arte, na ciência, navidae em cada fenômeno da arte, da ciência e da vida. Éovéu desdobrado; éa patuidade de Deus ${ }^{14}$.

\footnotetext{
9 Édouard Estaunié, Souvenirs, éd. Par Georges Cesbron, Paris, Genève, Librairie Droz, 1973, p. 53.

10 Ibid., p. 54.

11 lbid., pp. 55-56.

12 Gabriel-Jules Delarue, dit Strada, Essai d' un ultimum optimum ou Constitution scientifique de la méthode, Paris, librairie de L. Hachette et Cie, 1865.

13 Félix Ravaisson, La Philosophie en France au XIXè siècle, Paris, librairie de L. Hachette et Cie, 1889, pp. 154 sq. 14 Op. cit., p. 132.
} 
E ela também diz respeito ao ser, como o atestam as duas passagens seguintes:

O fato é a consequência da qualidade que tem o ser de estar patente por aquilo que é. É a patuidade do ser. É uma qualidade inerente ao ser e sem a qual ele não pode ser entendido. A manifestação pode ou não ser vista, mas ela é e é visível. O fato considerado em sua natureza é, portanto, a qualidade necessária do ser para estar em manifestação permanente ${ }^{15}$.

Tão logo descobrimos um fato, tocamos o ser; o contato é imediato. O fato sendo apenas a presença, a patuidade do ser reveste esse caráter de necessidade inerente ao ser. $\mathrm{O}$ fato é uma manifestação necessária, sendo o ser, mesmo estando na contingência, apenas um composto de qualidades necessárias. Todo fato, em sendo apenas um fato, é, portanto, sólido, porque mantém sua certeza diretamente e sem intermediário do ser que ele manifesta ${ }^{16}$.

Essas citações permitem ver mais exatamente o que Souriau entende por patuidade e em que medida, todavia, sem aderir à temática comunicativa da empatia, essa noção convoca a intuição. A patuidade do ser é objetivo, é uma "qualidade inerente ao ser", mas algo "deve nos fazer sentir isso".

O texto mais significativo a esse respeito é, sem dúvida, esta passagem d'A sombra de Deus:

Assim que o próprio eu é questionado no cogito, é estabelecido que a verdade primeira não é mais admissivel, exceto sob esta forma: há, presentemente o pensamento, então algo existe. Nunc cogitatur, ergo quid est. No entanto, é ainda duvidoso se o Cogitatur pode ser recebido como imediato, e se não se deve substituir, aí, por algo de mais direto e íntimo, que já trai essa palavra de pensamento. Não deve ser cogitatur, mas patefit. E se queremos precisar esta patui-

15 Ibid., p. 285.

16 Ibid., p. 306. dade contra o cogito cartesiano, podemos dizer que se trata da própria evidência na medida em que é primordialmente constituinte da experiência, não abstrato como, posteriormente atestante: A comprovação lida com um problema da verdade no julgamento, o que subverte a ordem das coisas ${ }^{17}$.

Esta reflexão de Souriau sobre o cogito parece-me, de fato, bastante pertinente na medida em que separa, oportunamente, do momento reflexivo do cogito - "há presentemente pensamento, então alguma coisa existe”- o momento não menos presentemente intuitivo de sua descoberta, em sua patuidade: patefit, ele escreve, escolhendo, desta vez, não patere, mas patefacere cuja semântica é muito próxima. Quando Souriau qualifica esse momento intuitivo de "a experiência do pensamento como punctum salian lucidum "18 pensamos não apenas no sentido anatômico do punctum saliens," ponto que salta", a primeira manifestação do coração no embrião - a experiência de que é um novo nascimento - mas também na oposição barthesiana do studium e do punctum.

Por minha parte, eu emprego a distinção de Souriau sobre a experiência em geral e, em particular, estética, ${ }^{19}$ recomendando que se evite a confusão entre a sensação direta da experiência e sua extrapolação como reação mais ou menos linguística. É a diferença entre achar algo bonito e dizer: "É belo!" Às vezes, apenas por ouvi-lo dizer, o encanto é quebrado... Pode-se achar algo

17 Étienne Souriau, L'Ombre de Dieu, Paris, Puf, coll. "Bibliothèque de philosophie contemporaine", 1955, p. 97. Voir Henri Declève, "L'Ombre de Dieu et le rétrait de l'Être (à suivre)", Revue philosophique de Louvain. Quatrième série, t. LXXXVI, n 69, 1988. pp. 37-58; <http://www.persee.fr/doc/ phlou_0035-3841_1988_num_86_69_6485>.

$18 \mathrm{lbid}$., p. 98.

19 Voir dans Dominique Chateau, L' Expérience esthétique : intuition et expertise (Presses universitaires de Rennes, coll."Aesthetica", 2010), la différence entre trouver beau et dire que c'est beau. 
belo sem querer dizê-lo, ou porque permanecemos em silêncio (quietos), ou porque a palavra parece, então, indiscreta, tanto quanto podemos dizer que algo é belo para não nos distinguirmos do grupo ou para não incomodarmos alguém...

Também descobri, recentemente, por ocasião de uma estada no Japão, que outro filósofo, mais desconhecido que Souriau, tinha diante de si uma interpretação comparável do cogito. Vale a pena esclarecer as circunstâncias.

Há, na universidade japonesa onde eu ensino estética, um filósofo, Ko Murase, que se interessou por Jules Lequier e, por essa razão, contribuiu para um colóquio fundamentado no n० 6 dos Cahiers Jules Lequier ${ }^{20}$. Ko Murase deu-o para mim e pude, assim, descobrir Lequier. A título sintomático de sua abordagem do cogito, ele escreve: "Eu existo; eis aqui uma certeza sobre a qual se deverá forçosamente apoiar aquela que se pretender superior a isso. Foi-me impossível explicar a união em mim mesmo do eu que sou e do eu que contempla, eu me sinto vivo, eles estão unidos, pouco importa saber como ${ }^{21}$.

Não encontrei nenhuma evidência de que Souriau tenha lido Lequier (mas meu conhecimento sobre seus arquivos é muito limitado). Ravaisson faz uma alusão muito breve a Lequier, referindo-se a Renouvier, que foi o primeiro a se interessar por este filósofo extraordinário ("uma parte das ideias de Renouvier sobre a liberdade, escreve Ravaisson, Ihe eram comuns com outro

20 Cahiers Jules Lequier, Jules Lequier, Une philosophie de la liberté, dir. par Goulven Le Brech et Frédéric Worms, Les Perséides, $n^{\circ}$ 6, 2016. L' article de Ko Murase s' intitule "Lequier et la recherche d'un commencement"; il y montre que Lequier se distingue de la quete philosophique habituelle du commencement, en ce qu' au lieu de commencer pour fonder, il entend fonder de commencer.

21 Jules Lequier, La Recherche d' une première vérité et autres textes, édition établie et présentée par André Clair, Paris, Puf, 1993,p.70. pensador que era seu amigo, Jules Lequier, do qual ele publicou, com cuidado devotado vários escritos póstumos"22).

Prémontval, Strada e, em menor escala, Lequier, Ravaisson e Renouvier: referências datadas que poderiam ser reduzidas a marcos históricos para puristas, os numismatas da filosofia (Valéry falava de numismatas da linguagem a propósito do belo) ou como o próprio índice de um pensamento datado. Referências, tais como Lequier, que também podem reaparecer com um novo brilho quando um pensamento simpatizante lhes tiver extraído a essência relegada ao esquecimento ou anteriormente despercebida. Souriau, em todo caso, distingue-se das referências mais ou menos bizarras de que se alimenta, naquilo em que o seu legado, tal como eu o percebo, é perfeitamente atual. Evidentemente, não falo de atualidade jornalística, mas da oportunidade de uma filosofia ser ainda consumível e influente, para além daquilo que a liga à sua própria modernidade. No que concerne a Souriau, outra prova dessa atualidade da herança acompanha seu pensamento: as instituições que ele fundou, sempre vivazes.

Mas eu cheguei imperceptivelmente, para além do comentário das fontes do filósofo, a uma reflexão mais pessoal sobre o interesse que tenho por ele na medida em que ele me acompanha e me ajuda na minha pesquisa em andamento. Volto, a este respeito, à instauração tal como ela está definida em A Correspondência das Artes:

O que é a arte? Se você tem que dizer algo geral, a arte é a atividade instauradora. É o conjunto das ações orientadas e motivadas, que tendem expressamente a conduzir um ser [...] do nada ou de um caos inicial até a existência plena, singular, concreta, atestando-se em indubitável presença $a^{23}$.

22 Op. cit., p. 115.

23 Étienne Souriau, La Correspondance des arts. Éléments d'esthétique comparée, Paris, Flammarion, coll. "Bibliothè- 
A instauração, aí, é um predicado da definição de arte. É um predicado cujo conceito me parece muito fecundo sob a condição de estendê-lo além do que Souriau poderia ou queria considerar quanto à arte. Num parênteses, um estudo de suas referências artísticas e seus gostos seria interessante para realizar (decepcionante, talvez?). Mas aqui não é essa a minha intenção. Eu preferiria explicar como eu interpreto e exploro a ideia da criação artística, tanto em geral quanto até a arte contemporânea. É principalmente por essa extrapolação respeitosa que eu considero o pensamento de Souriau o mais fecundo. Há autores diante dos quais nos inclinamos porque o que dizem nos cala a boca (no momento!), e outros com os quais pensamos porque o que dizem excita em nós a maturação das descobertas e profundidades ...

Assim estimulado por este conceito de instauração, provavelmente pouco inclinado a uma ortodoxia que, aliás, o estudo de Souriau não deixa de fragilizar, eu concebo três níveis ou modos de instauração. Primeiro, por fazê-la, pela poiética, isto é, um processo de fabricação que se abre através de várias fontes (de ideias, de matéria, etc.), que passa por várias operações (manipulação, construção) e fecha com um resultado (a obra ou o que toma o seu lugar). Em seguida, pela criação de mundos mais ou menos inspirados pelo existente, a memória ou a imaginação, mundos mais ou menos prováveis, em todo caso possíveis ao sentido ou, ocorrendo, eles instalam um dos mundos possíveis no real. Finalmente, pela declaração de arte, por decisão de um indivíduo, endossada por uma instituição, para propor como arte algo que não possui, necessariamente, propriedades artísticas - pensamos, obviamente em Duchamp e seus seguidores.

que de philosophie scientifique”, 1947 ; rééd. Paris, Flammarion, coll. "Sciences de l'Homme", 1969, p. 45.
Com base nisso, pode-se, portanto, considerar a possibilidade de colocar a ideia de instauração em relação com aquela, Valeryanna, da poiética: a produção vista do lado do resultado, dessa patuidade que nos toca na obra de arte, e ao lado do processo, da fabricação, da ação. Pode-se também considerar a instauração à luz dos mundos possíveis, da diégèse (uma teoria que desenvolvi, aliás); aí, ainda, do lado da ontologia, não mais do trabalho como ser, mas seres que a obra instaura; e pode-se considerar a patuidade que encoraja o desejo de ficção. Finalmente, pode-se imaginar uma patuidade do readymade, esta não obra, tão ostensivamente não obra, mas que é celebrada ainda como arte, subjugada pela simplicidade de seu modo de presença...

Deixo a questão em aberto. Há outro aspecto da ontologia de Souriau que me parece complementar, fundamentalmente, a geometria da instauração. Não se trata mais de considerá-la em termos de resultado, mas em relação aos planos em que ela opera. Deleuze e Guattari em O que é filosofia? fazem alusão à instauração segundo Souriau sobre o "plano de imanência"24. Eu sou mais inclinado a usar a palavra no plural: não um plano, de instauração ou de imanência, mas planos, de existência ou de realidade, e assim, de instauração. Nessa ideia de planos de existência ou realidade, acho que há uma das chaves da filosofia de Souriau.

Na verdade, ele aí retorna constantemente, à beira da obsessão. Encontramos também a ideia em Ter uma alma ${ }^{25}$ :

Não se tem o direito de falar filosoficamente de um ser como real, se ao mesmo tempo dizemos a espécie de verdade direta ou intrínseca que encontramos nele (refiro-me ao seu modo de estar no máximo do estado de pre-

24 Gilles Deleuze, Félix Guattari, Qu'est-ce que la philosophie ?, Paris, Minuit, coll. "Critique”, 1991, p. 44. 25 Op. cit., pp. 23 et 25. 
sença lúcida) também não dizemos em que plano de existência, por assim dizer, ele soou o seu toque de corneta; em que área foi atingido e com que força. [...] De um modo geral, pode-se dizer que, para saber o que é um ser, é preciso estabelecê-lo, construí-lo mesmo, seja diretamente (feliz a esse respeito, quem faz as coisas!) seja indiretamente e por representação, até o momento em que, elevado ao seu ponto mais alto de presença real e inteiramente determinado pelo que, então, se torna, ele se manifesta em sua completa realização, em sua própria verdade ...

\section{Que n'O universo fílmico'26:}

Um dos pontos que acho particularmente útil entre as aquisições desse trabalho em equipe é o desenvolvimento de um determinado vocabulário. Muito rapidamente percebemos que nosso trabalho foi muito afetado pela onda de termos em uso, pela impossibilidade de definir claramente, com palavras precisas e unanimemente aceitas, certos fatos ou noções básicas, em particular no que diz respeito aos vários tipos, ou melhor, aos vários planos de realidade em que esses fatos se situam e que fazem como a espessura do universo fílmico.

E que, ainda em outra forma, a de uma grade para apreender os modos de existência, no corpo proliferante dos Diferentes modos de existência e, de forma mais concentrada, na grade ontológica inaugural d'A Correspondência das artes - a dos modos de existência física, fenomenal, chosal e transcendente ${ }^{27} \ldots$

Assim, a existência que aparecia como um punctum, no momento suspensivo e reflexivo da intuição do EU (da patuidade), se desdobra,

26 Étienne Souriau (dir.), L'Univers filmique, Paris, Flammarion, coll. "Bibliothèque d'esthetique", 1953, p. 6.

27 Voir à ce sujet mon chap. IX, "L'ontologie filmique”, dans Philosophie d'un art moderne : le cinéma, Paris, L'Harmattan, coll. "Champs visuels", 2009. agora, em vários planos, na diferenciação e na espessura. Estes planos de existência ou de realidade capturam a ontologia não mais como um surgimento do ser pelo sentimento de ser, mas como uma experiência diversificada de representações plurais constitutivas até encontrarem a unidade de um ser ou de algo destinado aos seres - a unidade do indivíduo, do filme ou de qualquer outro objeto de comunicação pouco ou mais estético.

O que importa nessa ontologia que não se coíbe diante da complexidade, é que ela descobre constantemente modos mais ou menos separados ou associados - os seres não são compartiIháveis; as modas, o são. Na distribuição entre a ontologia do ser e a ontologia dos modos de ser, não há dúvida de que é preciso situar Souriau no segundo lado, ainda que ele não abandone o primeiro. Seja o começo do primeiro capítulo dos Diferentes modos de existência:

Se, quando se fala do ser, a esperança é vê-lo ficar numericamente sozinho, tão logo a multidão de seres que pensava distinguir o senso comum tornando-se fantasmagórica, estes pretensos seres, para reunirem-se ao ser e fundir-se nele, reúnem-se por tribos, cada uma dos quais segue a bandeira de um tipo particular de existência. Assim se reúnem entre eles todos os corpos e em seguida, todas as ideias. Ou as possibilidades, os contingentes, os necessários ${ }^{28}$.

Trata-se, aí, de uma perspectiva que coloca Souriau bem ao lado de filósofos que rejeitam a ontologia do ser, como Charles Peirce que, voltando as costas à tradição que extrapola em nome, Ser (Being), o verbo é (is), quando se supõe que "todas as coisas em que podemos pensar têm algo em comum", enquanto "não há nada desse gênero para observar"29, propõe

28 Op. cit., pp. 79-80.

29 Voir Charles S. Peirce, À la recherche d'une méthode (RM), trad. Michel Balat et Janice Deledalle-Rhodes, Perpignan, 
uma ontologia dos modos de ser, com, mais precisamente, "três modos de ser [30]": o modo de ser da possibilidade, o da atualidade e o da lei.Souriau e Peirce: eis aqui um bom tema para uma futura tese...

Permanecendo sobre a pista dos modos, eu terminarei esta espécie de argumentação (meio a meio pró-Souriau e pro domo), destacando o interesse que reveste, entre as categorias de modos, a distinção entre submodos representativo e apresentativo. Ela atraiu minha atenção particularmente na medida em que permite pensar ao mesmo tempo duas categorias de obras e, pelo menos em minha opinião, dois modos podem coexistir em toda obra. Testei - o em Filosofia da Arte Moderna: o cinema, no exemplo do filme que me permitiu pensar tanto do lado da ficção criativa dos mundos, quanto do lado dos procedimentos mais ou menos abstratos que podem competir ou acompanhar a ficção. Pensamos imediatamente na oposição entre o cinema narrativo e o cinema "abstrato". Mas, mais interessante do que esta clivagem de gênero, de grandes gêneros (que temos o prazer adicionar o terceiro grande gênero do documentário), observamos a possibilidade de obras nas quais narração e abstração se encontrem, compitam, se amalgamem. Filmes nos quais a narrativa oscila em sua representação, ou outros, em que a apresentação de configurações e de exemplos plásticos esboça uma narração.

O modo representativo diz respeito ao tipo de obra em que há uma "duplicação ontológica" entre a própria obra e os seres reais ou fictícios, cuja existência ela sugere (isso corresponde, deve-se notar, à instauração de mundos, diegeses); pelo contrário, "nas artes 'apresentativas', trabalho e objeto se confundem" [31]. Essa

Presses universitaires de Perpignan, coll."Études",1993, p. 89. distinção, que apliquei, então, a uma reflexão sobre a ontologia do cinema, também me permitiu esclarecer a noção de representação em minha mente. Isso supõe uma discussão, que conduzo em outro lugar, em torno desse mesmo conceito, às vezes limitado (até a semelhança), às vezes estendido (até cobrir tudo o que aparece).

Apenas para abrir uma perspectiva no momento de fechar o discurso, insistirei somente sobre um paradoxo: encontramos no modo "apresentativo", tipos de obras e de artes que se referem à representação no sentido do espetáculo (uma instauração ativa de alguma forma), o que sugere complicar o conceito de representação. A ideia me surgiu na elaboração deste texto; ao mesmo tempo, reconsiderei certa tradução da mimeses aristotélica por "representação" em vez de "imitação" [32]. E, aí ainda, Souriau é quem me inspira e me trabalha em profundidade, e tenho todos os motivos para acreditar que ainda não acabou... 